SECTION 21. Pedagogy. Psychology. Innovations in education.

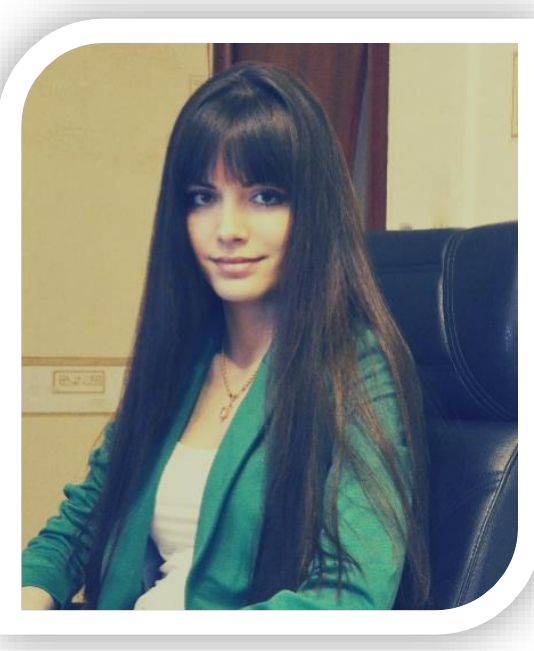

Marina Olegovna Pereskokova 4th year student, Department of special psychology,

Vyatka state University of Humanities,

Kirov, Russia

kadimova@inbox.ru

Svetlana Igorevna Smirnova candidate of Psychological Sciences, associate Professor of General and special psychology, lecturer of the chair of General and special psychology

Vyatka state University of Humanities, Kirov, Russia

\title{
INFLUENCE OF FEATURES OF THE EMOTIONAL STATE OF PEOPLE WITH CANCER ON THE INTERNAL PICTURE OF THE DISEASE
}

Annotation: This article shows the influence of emotional features of cancer sick people on the formation of an internal picture of the disease. of disease.

Key words: emotional sphere, cancer patients, anxiety, fears, phobias, internal picture

\section{ВЛИЯНИЕ ОСОБЕННОСТЕЙ ЭМОЦИОНАЛЬНОГО СОСТОЯНИЯ ЛЮДЕЙ, СТРАДАЮЩИХ ОНКОЛОГИЧЕСКИМИ ЗАБОЛЕВАНИЯМИ НА ВНУТРЕННЕЮ КАРТИНУ БОЛЕЗНИ}

\begin{abstract}
Аннотация: $B$ данной статье показано как влияют эмоциональные особенности онкобольных людей на формирование внутренней картины болезни.

Ключевые слова: эмочиональная сфера, онкобольные, тревожность, страхи, фобии, внутренняя картина болезни.
\end{abstract}

Одной из основных проблем современности является безжалостный рост и прогрессирование онкологических заболеваний по всему миру.

Россия - не исключение, рост онкологических заболеваний исчисляется сотнями тысяч каждый год. По эффективности лечения наша страна занимает далеко не первое место. Причин много и все они никак не разрешатся в одночасье: это и нехватка финансирования, нехватка технического оснащения и аппаратуры, ограниченное количество высококачественных специалистов в районах и на переферии и так далее [1-10].

Ни для кого не секрет, что благоприятная психологическая атмосфера в ходе процесса лечения, хоть и не гарантирует $100 \%$ исцеление от болезни, но дает некий приток жизненных сил и повышает сопротивляемость организма. У человека появляется стимул и стремление.

Наверное, у всех людей, по крайней мере, у большинства точно слово рак, онкология ассоциируется со словами смерть, старх, безысходность и отчаяние. Для человека, который узнает, что у него обнаружили страшный диагноз, очень важна моральная поддержка, при чем не только со стороны семьи, но главным образом со стороны профессионалов и специалистов. 
Довелось ли вам когда-либо посещать онкологическую больницу, стационар или поликлинику? Жутко ужасающая давящая атмосфера, совершенно не расположенные к общению врачи, такое чувство, что у всего медперсонала наступило эмоциональное выгорание, больные для них как содержимое конвеера.

Стоит отметить, что для человека, с подобным диагнозом имеет место быть в начальном периоде некая фаза шокового состояния, когда он сам пребывает в состоянии растерянности и ему просто необходимо получить какую-то информацию. Что делает человек в 90\% случаев, он отправляется за информацией в интернет, натыкается на кучи негативных отзывов, тем самым окончательно добивая себя и в некоторых ситуациях даже не обращается за помощью в больницы вовремя, теряя тем самым драгоценное время. В других случаях он обращается за помощью к врачу и первый вопрос логичен и ясен: «Доктор как мне быть? Что мне делать». И именно на этом этапе во многом зависит успех будущего этого человека. Само собой у таких профессоров-специалистов в день проходит не один «новоиспеченный» больной и давать всем добрые советы и наставления он не в силах. Но нужно уметь правильно преподнести человеку информацию а не отодвинуть его от себя, сказав, что, мол не обязаны каждому все разъяснять.

Онкобольной человек - это человек с ограниченными возможностями здоровья, который вынужден во много себя ограничивать, терпеть социальную а порой и сенсорную депривацию, логично придти к выводу о том, что у лиц страдающих онкологическими заболеваниями появляется ряд психологических особенностей, которые безусловно необходимо учитывать.

Повышенная внушаемость, восприимчивость, предвзятое отношение к происходящему, поиски двойного смысла, уверенность в обмане окружающих, собственное самоуничижение и т. д.

Как правило, родные и близкие люди, стараясь помочь, сами не замечают, как еще больше накаляют обстановку Ощущение беспомощности, невозможности помочь близкому заставляет родственников психологически отстраняться от онкобольного, который и так чувствует, что к нему относятся по особому другие люди, включая медицинских работников. Это вызывает болезненное ощущение погребенности заживо.

Такая атмосфера, которая складывается вокруг человека с онкологическим заболеванием, способствует полному пересмотру и переосмыслению жизни, а отношение окружающих напрямую оказывает влияние на внутреннее эмоциональное состояние человека, которое в свою очередь оказывает негативное влияние на отношение больного к своему недугу.

Наше исследование проводилось на группе людей возраста 20-30 лет имеющих онкологические диагнозы, находящихся в стенах онкологических клиник или состоящих на учете в онкологических поликлиниках (в данный момент все опрашиваемые не находились в состоянии ремиссии).

Мы изучали влияние особенностей эмоционального состояния таких людей на внутреннюю картину болезни.

Обследование началось с вопросов об осведомленности, о собственном состоянии. Несмотря на то, что обследуемая категория людей, это активные молодые люди, знающие, где и как можно лучше найти информацию о своей болезни, достаточно большой процент (32\%) пожелал остаться в неведении, положившись 
исключительно на прогнозы и отклики медицинского персонала, «будь как будет, я ничего не хочу знать», остальные испытуемые, досконально перешерстили всю информацию о собственном заболевании. Стоит отметить, что эмоциональный фон был значительно ниже у людей, предпочетших остаться в неведении.

Примерно 20\% опрошенных характеризовали себя как активных и уверенных в себе, в то время, как большинство, а именно 80\% отмечали появление меланхолических черт, апатии, неуверенности в себе и в своем будущем.

Отношение к болезни весьма вариативно: примерно 6\% испытуемых верят в собственный успех перед недугом, 52\% не верят в возможность излечения и характеризуют свою болезнь не иначе как бесперспективное будущее, $48 \%$ полагаются на волю судьбы.

Большинство испытуемых, в ходе опроса выдвигали схожие жалобы: это нарушение сна, чувство тревоги, беспокойства, страх боли, страх неизвестности, смерти, страх за детей, у которых велик риск остаться одними, страх лишиться работы, супруга, статуса.

Все эти жалобы испытуемые совершенно адекватно соотносят с имеющимся у них диагнозом - рак.

В основном у онкобольных людей наблюдается стабильно пониженный фон настроения. Затянувшаяся дисфория сначала способствует появлению депрессивных, унылых состояний, плаксивости, повышенной тревожности, больные требуют и ждут поддержки и участия в их жизни, понимания и сочувствия в первую очередь родных и близких людей, огромное значение так же уделяется роли медицинского персонала, от врачей обычно тоже ждут моральной поддержки, теплых и успокаивающих слов.

Позднее вследствие длительного психоэмоционального напряжения и отсутствия полноценного сна, в связи с чрезмерным уходом, опекой со стороны родных у больных начинает формироваться образ собственной немощности, обреченности, как следствие появляется раздражительность, агрессивность, вспышки гнева, с резкой следующей апатией, отсутствием веры в себя и благоприятный исход болезни. Больные уходят в себя, могу перестать говорить, общаться, реагировать на родных и близких.

Большинство испытуемых характеризуют свою болезнь как отталкивающую, пугающую, сильную, злобную, непривлекательную.

На фоне собственной болезни себя испытуемые характеризуют не иначе как: слабые, пассивные, безвольные, рабы, бесперспективные, никчемные.

В связи с этим можно сделать вывод о том, что под влиянием болезни значительные изменения претерпевает самооценка больных (заниженная самооценка).

В основном испытуемые живут прошлым: яркими воспоминаниями, событиями, в диалогах часто обсуждают дела минувших дней. Планы на будущее весьма расплывчаты: «мне бы до конца недели дожить...», «год переживу там видно будет...», «мой главный план и цель - дожить до выпускного дочки» и тд. Именно при разговорах о будущем наблюдается повышение тревожного состояния и напряженности.

У значительного числа больных отмечается наличие фобий и навязчивых идей: «я умру всем будет легче», «они только и ждут, чтобы я поскорее умерла», «мне 
суждено было умереть молодой», «после мой смерти хуже никому не будет, потому что я ни на что не годный человек».

Таким образом, данные полученные в ходе опросов и интервью не противоречат, а взаимодополняют друг друга. Эмоциональные нарушения, а именно: страхи, фобии, повышенная тревожность, психоэмоциональное напряжение, влияют на активность и самооценку больного, что в свою очередь заставляет посмотреть человека на свою болезнь как на нечто ужасное, абсолютно бесперспективное и непреодолимое.

Не стоит забывать, что от того как человек относится к своей болезни, зависит общий успех терапии. В связи с этим стоит пересмотреть подход к построению общения с онкобольными людьми на всех уровнях, начиная с семьи, родных, друзей, заканчивая медицинским персоналом, стоит отметить, что последним отводится особенно важная роль, потому, что для больного человека врачи возводятся в ранг божества, которое способно решить и вершить их судьбы.

\section{References:}

1. Астахов, В. М. Функциональный подход к изучению состояния тревоги. [Текст]/ В. М. Астахов. - М.: Политиздат., 1999. - 47 с.

2. Блинов, Н. Н. Отношение онкобольных к своему диагнозу. [Текст]/ Н. Н. Блинов - М.: Аспект Пресс, 1990. - 380 с

3. Вундт, В. Психология душевных волнений. [Текст]/ В. Вундт. -М.:, 1993. - 65 c.

4. Коблер-Росс. О смерти и умирании. [Текст]/ Коблер-Росс. - Киев.: София., 2001. $-320 \mathrm{c}$.

5. Коган, Б. М. Стресс и адаптация. [Текст]/ Б. М. Коган. - М.: «Знание», 1980. - 64 c.

6. Алавидзе, Т. А. Социальная психология в современном мире. [Текст]/ Т. А. Алавидзе. - М.: Политиздат., 2002. - 56 с.

7. Андреева, Г. М. Социальная психология. [Текст]/ Г. М. Андреева - М.: Аспект Пресс, 2001. - 380 с

8. Бодалев, А.А. Восприятие и понимание человека человеком. [Текст]/ A.А. Бодалев. - М.: Политиздат., 1982. - 78 с.

9. Бодалев, А. А. Личность и общение. [Текст]/ А. А. Бодалев. - М.:, 1983. -35 с.

10. Лурия, А.Р. Внутренняя картина болезни и атрогенные заболевания. [Текст]/ А.Р. Лурия. - М.: 1980.-360с. 